\title{
The Role of Non-Contrast Chest CT in Suspected or Confirmed Coronavirus Disease 2019 (COVID-19) Pediatric Patients
}

\author{
Rishi Philip Mathew ${ }^{1}$ (D) Merin Jose ${ }^{1}$ (D) Ajith Toms $^{1}$ (D)
}

Received: 8 April 2020 / Accepted: 4 May 2020 / Published online: 18 May 2020

(C) Dr. K C Chaudhuri Foundation 2020

To the Editor: The Coronavirus disease 2019 (COVID-19) is caused by a recently discovered novel enveloped RNA betacorona virus called severe acute respiratory syndrome coronavirus-2 (SARS-CoV-2). COVID-19 is highly contagious, and as of April 26, 2020, approximately 2,900,422 confirmed cases have been reported worldwide with 203,055 related deaths.

COVID-19 is diagnosed by real time reverse transcription polymerase chain reaction (RT-PCR) assay. However, the test has several limitations and a sensitivity of only $30-70 \%$ at initial presentation; additionally, a negative RT-PCR does not rule out COVID-19 [1]. Chest radiographs (CXRs) and computed tomography (CT) have been widely used for evaluating COVID19 patients. However, CXRs have low sensitivity (20\%) and may appear normal during the early stage of the disease and therefore are not recommended as the 1st line imaging tool [2].

Chest CT is now the widely accepted imaging tool for evaluating suspected or confirmed COVID-19 cases, as well as for monitoring therapeutic response and follow-up. When compared to RT-PCR, the reported sensitivity, specificity and accuracy of chest CT are 97\%, 25\% and $68 \%$ respectively, while the positive and negative predictive values are $65 \%$ and $83 \%$ respectively. Additionally, $60-93 \%$ of the patients can have positive CT findings much before the initial RT-PCR tests turn positive [3].

COVID-19 disease in the pediatric population is mostly mild [4], with the most common $\mathrm{CT}$ findings being unilateral or bilateral subpleural ground-glass opacities, and consolidations with surrounding halo sign [5]. Additional findings include- peribronchial distribution of disease and bronchial wall thickening. As the disease progresses, the consolidations can extend diffusely giving a "white lung" appearance accompanied by air-bronchogram sign. During the recovery stage,

Rishi Philip Mathew

dr_rishimathew@yahoo.com

1 Department of Radiology, Rajagiri Hospital, Chunangamvely, Aluva, Kochi, Kerala 683112, India following treatment, the consolidations reduce in size and density, having a ground glass appearance. Pleural effusion and lymphadenopathy are rare [5].

Based on this clinical information, we felt the need to bring to the attention of the pediatric physicians and surgeons, especially those battling against confirmed COVID-19 cases, the potential of chest $\mathrm{CT}$ and the valuable information it can provide. We feel a combination of pathogen detection using RT-PCR and early chest CT including follow-up imaging should be incorporated into the protocol when managing symptomatic pediatric COVID-19 patients.

\section{Compliance with Ethical Standards}

Conflict of Interest None.

\section{References}

1. Kanne JP, Little BP, Chung JH, Elicker BM, Ketai LH. Essentials for radiologists on COVID-19: an update- radiology scientific expert panel. Radiology. 2020. https://doi.org/10.1148/radiol.2020200527.

2. Choi H, Qi X, Yoon SH, et al. Extension of coronavirus disease 2019 (COVID-19) on chest CT and implications for chest radiograph interpretation. Radiol Cardiothorac Imag. 2020;2. https://doi.org/10. 1148/ryct.2020200107.

3. Ai T, Yang Z, Hou H, et al. Correlation of chest CT and RT-PCR testing in coronavirus disease 2019 (COVID-19) in China: a report of 1014 cases. Radiology. 2020:200642. https://doi.org/10.1148/radiol. 2020200642.

4. Chen A, Huang J, Liao Y, et al. Differences in clinical and imaging presentation of pediatric patients with COVID-19 in comparison with adults. Radiol Cardiothorac Imag. 2020;2. https://doi.org/10. 1148/ryct.2020200117.

5. Xia W, Shao J, Guo Y, Peng X, Li Z, Hu D. Clinical and CT features in pediatric patients with COVID-19 infection: different points from adults. Pediatr Pulmonol. 2020;55:1169-74. https://doi.org/10.1002/ ppul.24718.

Publisher's Note Springer Nature remains neutral with regard to jurisdictional claims in published maps and institutional affiliations. 